\title{
Research of the Economic Frictional Resistance of Network of Hot Water Heating
}

\author{
Yue Xingzuo \\ Wuhan institute of shipbuilding technology \\ wuhan china \\ 84771162@qq.com
}

\begin{abstract}
Heating industry as a basic
industry overall, leading effect on the development of the national economy, and is closely related to people's life. Since the founding of our country heating industry has been rapid development, but also there are very serious problems. China's building energy consumption is 2-3 times abroad, especially the heating energy consumption, and China is an energy scarce countries, especially the per capita resources, energy-saving potential in the issue.Connected to the heat source and heat between users of heating pipe network for heating and heating quality reliability is very important. In the heating pipe network life cycle, influences the stage of design of investment will reach $85 \%$, the parameter selection and especially select specific frictional resistance of safety reliability of life cycle cost and network play a decisive role. At present our country in specific frictional resistance when selected, mainly on the basis of former Soviet Union's experience and recommended by $30-70 \mathrm{~Pa} / \mathrm{m}$ or $40-80 \mathrm{~Pa} / \mathrm{m}$. With the development of economy and the heating enterprise, this range meets the need, whether the economy, need to be further studied. Optimization of the heating pipe network, so that resources to maximize the improvement of people's life, reduce heating costs, is of great significance to our country energy conservation.
\end{abstract}

Keywords-heating pipe;network; the frictional resistance;life cycle cost;energy

\section{INTRODUCTION}

Heating industry as a basic industry overall, leading effect on the development of the national economy, and is closely related to people's life. Due to the current energy and environmental issues more and more attention to sustainable development,energy conservation, environmental protection, economy has become the basic national policy of our country".

The central heating has been the rapid development of its own characteristics, it is inseparable, central heating and decentralized heating comparison, has many advantages: 1. Improve the utilization rate, energy saving energy. The heating unit integrated heat cogeneration efficiency can reach $85 \%$, and the thermal efficiency of the small boiler decentralized 50\%-60\%. It is the good environmental benefits can be small boiler and fuel, make a large number of dispersed ash piled covers an area of,for afforestation, improve the appearance of the city. The fireman low reduce transportation volume and fuel, the amount of ash and scattered, reduce operating costs, improve environmental sanitation. The easy to realize scientific management,improving the heating quality. The good social benefit. Urban central heating for the convenience of people's daily life, save construction of precious land, alleviating urban electric tension is very important. Building energy consumption in China in 2001 accounted for the total consumption of $27 \%$, and the heating and air conditioning ventilation energy consumption accounts for the national total building energy consumption in developed countries is about $2 / 3$, the current building site in general total energy consumption of about $1 / 3$. Therefore, urban centralized heating is an important way of energy saving and environmental protection, is one of the major infrastructure of urban modernization, but also the economic development,One of the important sign of improving the people's material life ".

With the steady increase of our central heating scale, people for the city central heating requirements have not only limited to the heating scale unceasing expansion,the higher requirements of energy utilization ratio and the reliability of the heating system is presented. Energy conservation in the engineering design, give full play to various applications, efficiency of the network, to avoid the occurrence of greater economic losses, so our country has been in the optimization and the economic development of the calculation and analysis of heat supply network. The central heating is a complex system engineering, system optimization including energy optimization, parameter optimization, and optimization of heating supply network to adjust control optimization.

Outdoor heating pipe network is part of the largest investment, construction of the most onerous in heating system. Have great effect of heating the extra net network form for the

system reliability, maneuverability, heating operation is convenient and economic benefit. Outdoor heating pipe network in the whole life cycle of investment decision stage, design stage, construction stage of planning, use, repair, scrap residual recovery stage. In each stage of outdoor pipe network life cycle, decisionmaking and design stage is the most important influence of engineering cost, also saves the most likely stage. Experts point out that, in the planning and design stage,the possibility to influence project investment of $85 \%$; in technology design stage, the possibility to influence project investment is $35 \%$ $\sim 75 \%$; in the construction design stage, the possibility to influence project investment is $5 \% \sim 35 \%$. According to the research analysis, only the general design construction is equivalent to the whole life cycle cost of $1 \%$, but it is the impact of this less than $1 \%$ of the cost of investment is as high as more than $75 \%$. Generally speaking, in the same function conditions,technical and 
economic reasonable design, the engineering cost can be reduced from $5 \%$ to $10 \%$, and even up to $20 \%$.

\section{RESEARCH METHODS}

The design level of heat supply network is reflected in the meet the heat user heat demand conditions, the thermal energy loss is reduced to a minimum, and less investment, good operating stability and heat supply network each sink hydraulic

balance degree high aspects. As everyone knows, in the design of the outdoor hot water pipe network, known on the Internet the heat users the flow rate of hot water or heat load, to determine the diameter and the pressure loss of each pipe network, is the heating pipe network hydraulic calculation for many tasks in the most basic, the most important step. A table or diagram using the hydraulic calculation, design calculation, in order to determine the pipe's diameter, in known its flow or thermal load conditions, must know the pipe segment of the size of the average frictional resistance. Under normal circumstances, the pressure drop tube segment value is unknown, this requires an average specific frictional resistance of preselected in the calculation, according to the pipe flow or thermal load, the average specific frictional resistance reference preselected, check calculation table or graph, determine the parameter calculation of pipe diameter. This predetermined average specific frictional resistance is directly related to the cost and the operation cost of network level, such as the selection of specific frictional resistance of $\mathrm{R}$ value is greater, then needs the smaller diameter, infrastructure investment and the loss of heat pipe is also less but network circulating pump head is increased, the operation of the electric consumption increases. Such as the use value is small, the opposite effect. Thus, we introduce the concept of economic specific frictional resistance.

The economic specific frictional resistance is in the hydraulic calculation of pipe network, so that in the whole life cycle cost minimum and the frictional resistance of the. In the hydraulic calculation of outdoor pipe network, China's traditional recommendation specific frictional resistance in $30 \sim 70 \mathrm{~Pa} / \mathrm{m}$ or $40 \sim 80 \mathrm{~Pa} / \mathrm{m}$, with the development of economy and the heating enterprise, this is the scope of economy, whether it is suitable for the present development, need to be further studied. By engineering economic analysis, build a mathematical model for solving the economic specific frictional resistance, solution has significance to the actual project data, in order to avoid unnecessary losses to the development of economic construction.

The connection between the heat source and heat users of water network is the centralized heat supply system important constituent, its operation is normal or not directly related to the life of the residents. Heating pipe heating systems is investment most, the most heavy construction part, has great influence on heating outside the network form for the system reliability, heating mobility, operation is convenient and economic benefit.

Life cycle cost of heating pipe includes economic cost and social cost and environmental cost. In this study only considered in economic cost. The economic cost of heating pipe network by setting the fee and maintenance fee composition. Set the charge other costs include construction and installation costs and construction. Other costs include: building management fees, feasibility study fees, research and test fees, survey and design fees, environmental impact assessment fees, site preparation and temporary facilities fee, engineering insurance premium, the joint commissioning

preparation and organization

expenses. Network setup fee equal

costs, production

the network infrastructure investment costs. Maintenance costs include: management fees, labor costs, electricity, water fee, maintenance fee (maintenance material costs,labor costs, external maintenance), major repairs, heat loss of pipe network costs, cost of removal, residual value.

In the urban planning and construction, according to the city's industrial, commercial,traffic development and political and economic status of the layout of the city, each have their own characteristics, so the city heat supply network has a variety of different types of. In addition, the network construction and transformation of the original city must also be determined according to the actual situation of the city,so it can be said that the heating network each different city has different size and type. According to the engineering design to provide a reference data, find out the heating network representative. Should have common properties of general network has inherent connection can elicit different heat supply network, and has universality and practical significance of extensive, known as the "virtual network".

Virtual network should have the following properties: virtual network itself does not exist, but having characteristics in common with general heating network, statistical analysis and calculation for any city heat supply network, and the actual results to differ significantly. As everyone knows, the heating network types except according to geographical conditions, heating radius, buildings distribution is different, also influenced by load density. To conduct unified analysis of these complex situation,internal connection must find the city heat supply network in heating network, which can reflect the characteristic parameters of common. In the heating under the same condition (technical and economic parameters under the same ratio), the material characteristics of the network and the number of the heating water flow generally tends to a constant, obviously this law reveals the internal relations between different network, because the material characteristic number directly reflects the heating district heating network load density and branch development status. Reflects the same heating network arrangement, and can be used as the characteristic parameters of common reflect heat supply network. That is to say, heat supply network for the total length of backwater pipe should exist in the variables in the virtual network. 


\section{THE RESULT ANALYSIS}

The method is adopted, the life cycle cost of single parameter calculation and analysis of specific frictional resistance as independent variables, other parameters can be adjusted to the ways of the economic specific frictional resistance.

In order to supply and return water the temperature of 130/70 DEG c., sleeve compensation mechanical excavation for example to explain the economic specific frictional resistance, economic pipe diameter, the economic flow velocity variation trend along with heating scale change, and verified in the pipe network design, the traditional friction resistance recommended selection range $30 \sim 70 \mathrm{~Pa} / \mathrm{M}$ or $40 \sim 80 \mathrm{~Pa} / \mathrm{M}$ whether the economic.

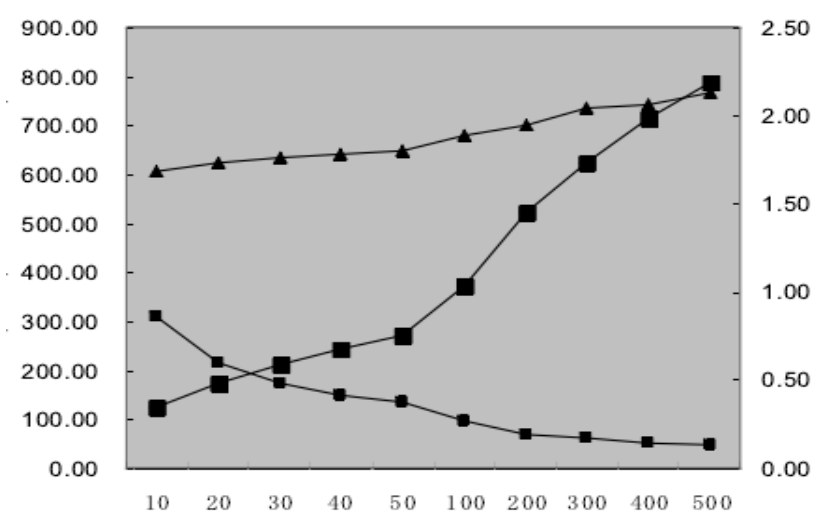

Figure 1. variety curve of economic specific frictional resitance,calibre,flow-speed of type scales of $130 / 70{ }^{\circ} \mathrm{C}$ heating pipenetwork

As can be seen from the graph, the economic specific frictional resistance decreases with increasing heating scale, the economic diameter and economic velocity increases with the increasing of heat scale, but the variation of flow velocity is not. The economic specific frictional resistance varies with the heating scale is very obvious. When heating the scale of less than 2000000 square meters, calculated the economic specific frictional resistance in the range of $80 \sim 360 \mathrm{pa} / \mathrm{m}$, greater than the recommended range, at this time if you still use the recommended values to select specific frictional resistance, will lead to partial large diameter, initial investment increases. When the heating scale is greater than or equal to 2000000 square meters of less than 5000000 square meters, economic specific frictional resistance of the calculated value is in the recommended range of. As can be seen from the table, the economic specific frictional resistance decreases with increasing heating scale, in heating the size of 5000000 square meters, the economic specific frictional resistance minimum mean value of $40 \mathrm{~Pa} / \mathrm{m}$, along with the development of district heating in our country, the heating scale gradually increases, friction resistance selection will be smaller. But the specific frictional resistance hours will lead to investment increases, using relay station then way can improve the friction resistance, through the technical and economic analysis, so that the minimum life cycle cost network.

As can be seen from the calculations, heating scale is greater than or equal to 2000000 square meters, this range is recommended in the

From 30 to $70 \mathrm{~Pa} / \mathrm{m}$ or $40 \sim 80 \mathrm{~Pa} / \mathrm{M}$ specific frictional resistance range. That is to say the urban heat network scale is larger, can

Use the recommended range of selecting specific frictional resistance, and with small friction resistance can be chosen large. But no flow of heating medium

Should be more than $3.5 \mathrm{~m} / \mathrm{s}$, specific frictional resistance should not exceed $300 \mathrm{~Pa} / \mathrm{m}$. The calculated maximum economic specific frictional resistance of up to $412 \mathrm{~Pa}$

/ $\mathrm{m}$, so in the selection of specific frictional resistance is to consider the economic but also consider whether it meets the design specification.

Effect of heating scale on the economic diameter is larger, the rate of change of great. While the economic impact velocity is relatively

Small, economic velocity values in the range of $1.69 \sim 2.14 \mathrm{~m} / \mathrm{s}$.

\section{THE RESEARCH CONCLUSION}

Through using the method of life cycle cost for a single parameter calculation and analysis of specific frictional resistance as independent variables and other parameters can be adjusted to the ways of the economic specific frictional resistance.Research and Analysis on hot water heating a net economic specific frictional resistance in expansion, using the mathematical method to solve the target modeling and obtained numerical solutions, through calculation and analysis, the main conclusions are as follows:

(1) when the pipeline type determined, through the conclusion of supply and return water temperature, $150 / 70,140 / 70,130 / 70,120 / 70,110 / 70$ of different calculation:specific frictional resistance in traditional recommendation $30 \sim 70 \mathrm{~Pa} / \mathrm{m}$ is not entirely scope economy, scale of less than 2000000 square meters of heating, economic specific frictional resistance range calculated were greater than the recommended range at $80 \sim 360 \mathrm{~Pa} / \mathrm{m}$, at this time if you still use the recommended value selection of specific frictional resistance, will lead to too large diameter, initial investment increases. When the heating scale is greater than or equal to 2000000 square meters of less than 5000000 square meters, economic specific frictional resistance of the calculated value is in the recommended range of. While the economic specific frictional resistance with increasing heating scale decreases gradually in the heating,the size of 5000000 square meters, the economic specific frictional resistance minimum mean value of $40 \mathrm{~Pa} / \mathrm{m}$, along with the development of district heating in our country, the heating scale gradually increases, friction resistance selection will be smaller.

(2) through the comparison of the specific frictional resistance heating scale,economic specific frictional resistance decreases with increasing heating area, reduce the heating area increased. 
(3) the range of heating network economic velocity is $1.6 \sim 2.2 \mathrm{~m} / \mathrm{s}$, its increase with the increase of heating area and.

(4) analysis to the economic specific frictional resistance through the supply and return water temperature difference, temperature difference selection has great influence on the economic specific frictional resistance, temperature changes every10 DEG $\mathrm{C}$ specific frictional resistance change rate in $7 \% \sim 12 \%$ between; friction resistance increases with the increase of temperature difference, the greater the greater the temperature difference between the friction resistance, large temperature difference big frictional resistance the temperature difference is small, small frictional resistance; influence of temperature on the economic diameter is the diameter decreases with the increase of temperature difference, under the same conditions, small temperature difference in large diameter, large temperature difference between small diameter; temperature 10 $\mathrm{C}$ per change economic pipe diameter change rate in $5 \%$ $\sim 10 \%$ between; temperature has no effect on the economic flow velocity. In the same condition as far as possible to take the large temperature difference of small diameter.

(5) Through the analysis on the temperature of supply water temperature is different, the same economic specific frictional resistance in Temperature difference at the same time, water temperature has no influence on the economic specific frictional resistance, pipe diameter and flow velocity.

(6) effects of compensation and the excavation method of different economic specific frictional resistance, the diameter is very small, basically no influence on velocity.

(7) comparing with the annual cost calculation method, the two results are basically the same. If considering the various costs of life cycle cost, calculation results of the two may be the gap, this for the latter to discuss.

(8) through the sensitivity analysis of the factors affecting the economic specific frictional resistance, determined the weight of each factor influence,

On the existence of an actual project the actual project were compared to determine the influence factors, the more obvious is mainly: the material factor, steel prices, local resistance accounted for the percentage of the main trunk of unit area, heat index,price, discount rate, support network accounts for the main trunk than seven sensitivity factors, the price of the compensator and artificial cost, interface price,sand, steel bar, heat price, maintenance rate is not sensitivity factors. The material factor, price, local resistance to impact the percentage of maximum.

\section{PROSPECT}

This project is using the method of life cycle cost of heating a network specific frictional resistance analysis and calculation was made. Life cycle cost while abroad for many applications, especially USA. But the domestic in the heating engineering it is rare, so need to be further studied.
In the analysis of life cycle cost, only consider the economic cost, social cost and environmental cost has not been considered, and the economic cost analysis because my level is limited and not fully consider.

This topic is on a network to do the analysis computation, does not consider the net two times, and two times in the economic analysis also plays an important role. And do the electric energy calculation in the whole network is only used qualitative methods to adjust the control network, and the actual work of not only this kind of mode, and quantity regulation, quality regulation etc.. According to the literature quality regulation power consumption, is not conducive to energy conservation, especially heating system particularly large especially. A network using quantity regulation is the trend of development, the adjustment of the amount of using variable speed circulating water pump, can save power consumption about $40 \%$ years. And with the development of our country and urban heating, heating system will be more and more big.

The hypothesis of heating network pipe flow is continuous change, and the end of the pipeline flow is zero, the application of linear method to research economic specific frictional resistance, but heat pipe section inside the actual flow is not continuous changes, the end of the pipeline flow is not zero. These factors need further research, to refine the model and improve the precision of calculation, reduces the error.

\section{REFERENCES}

[1] Bojic, M, Trifunovic.N. Linear Programming Optimization of Heat Dis tribution in a District-heating System by Valve Adjustments and Substation Retorfit.Building and Environment, 2000,(2)-1 51 - 159

[2] Kanina.L.P.Improvement in Reliability of operation of Heat supply system During Short-term interruption of power supply.Management Science.2003(5):18 — 20P

[3] Sun Jian, " Performance of absorption type heat pump with mixture solution of lithium bromide and lithium nitrate," HV\&AC,2010.

[4] Ye Da fa, "Common energy saving methods and control for air conditioning systems ,",2012.

[5] Wang JiangJiang,Zhang Chun,Fa,Jing You,Yin.Multi-eriteria analysis of eombined cooling,heating and Power systems in different climate zones in China[J].Applied Energy,2010,87(4):1247 - 1259

[6] Zhang Xuedong, "Analysis of Heat Transfer Performance and Design of Single effect Lithium Bromide water Absorption Chillers Using Plastic Pipes”. Applied Energy Technology,2010.

[7] Liang Chenghao . "Inhibition effects of PMA /SbBr3 complex inhibition copper and cupronickel in LiBr solution" .Transactions of Nonferrous M et a $1 \mathrm{~s}$ Society of $\mathrm{C}$ h i na , 2005 , 15 (3) : 625630 .

[8] Gebreslassie, Berhane H, Medrano Marc. Optimum heat exchanger area estimation using coefficients of structural bonds: Application to an absorption chiller. International Journal of Refrigeration, 2010, 33:529-537.

[9] Gustavo R. Figueredo, Mahmoud Bourouis, Alberto Coronas. Thermodynamic modeling of a two-stage absorption chiller driven at two-temperature levels . Applied Thermal Engineering, 2008,28:211-217.

[10] Heejin Cho, Pedro J. Mago, Rogelio Luck,et al. Evalutaion of CCHP systems performance based on operational cost, primary energy consumption, and carbon dioxide emission by utilizing an optimal operation scheme. Applied Energy, 2009, 86:25402549 . 